\title{
Produzir saberes sobre o trabalho: Um método em Psicologia
}

Deivis Perez. Universidade Estadual Paulista Júlio de Mesquita Filho.

\section{Resumo}

Este estudo teórico teve como objetivos: a) identificar e discutir os fundamentos epistemológicos que condicionaram o desenvolvimento da autoconfrontação; b) metodizar uma proposta de aplicação deste dispositivo. A autoconfrontação a qual referimos é aquela que emergiu no contexto da Clínica da Atividade, ramificação da Psicologia do Trabalho, com raízes na Psicologia Histórico-Cultural de Vigotski. Esse dispositivo caracteriza-se por ser, simultaneamente, um instrumento de coanálise e possível transformação do trabalho, protagonizada por trabalhadores mediados por um pesquisador e, também, de recolha e exame dos dados de investigações científicas. A autoconfrontação tem sido utilizada por pesquisadores da Educação, Linguística Aplicada e Psicologia, mas, a despeito disso, observa-se uma lacuna nos estudos especializados no que diz respeito a elucidar os elementos norteadores dos seus usos. Em face disto, buscamos contribuir com o registro de uma leitura da Clínica da Atividade e uso desse método.

Palavras-chave: psicologia do trabalho; metodologia de pesquisa; clínica do trabalho.

\begin{abstract}
Creating knowledge about the work: A method in Psychology. This study had as objectives: a) identify and discuss the epistemological foundations that contributed to the development of the self-confrontation; b) methodize a proposal of application of this device. The self-confrontation was created in the Clinical Activity context, branch of Social Work Psychology, with its roots in the Vigotski's Historical-Cultural Psychology. This device is characterized for being can be defined, simultaneously, an instrument of co-analysis and possible transformation of work performed by workers mediated by a researcher and, at the same time, of scientific research data collecting and data analysis. The self-confrontation has been used by researchers from Education, Applied Linguistics and Psychology, but, in spite of that, it is possible to observe a gap in the specialized studies in relation to the clarification of the guiding elements of their uses. For this reason, we aim to contribute to the registration of a reading of the Clinic of Activity and use of this method.
\end{abstract}

Keywords: work psychology; research methodology; clinic of work.

\section{Resumen}

Producir conocimiento sobre el trabajo: Un método en Psicología. Los objetivos del presente estudio fueron: a) identificar y discutir los fundamentos epistemológicos que han permitido el desarrollo de la auto-confrontación; b) estructurar una propuesta de aplicación de esta metodologia científica. La auto-confrontación surgió en el campo teórico de la Clinica de la Actividad, que forma parte de la Psicología del Trabajo, y tiene fundamentos en la Psicología histórico-cultural de Vigotski. Esta es una metodología de co-análisis y transformación del trabajo llevado a cabo por los trabajadores mediadas por un investigador o un psicólogo, y también se utiliza como una técnica para recolección y análisis de datos de las investigaciones científicas de datos. La auto-confrontación ha sido utilizada por los investigadores de la Educación, Lingüística Aplicada y Psicología, pero a pesar de eso, hay un vacío en los estudios especializados en materia de dilucidar los elementos rectores de sus usos. En vista de esto, en este artículo he tratado de señalar una interpretación de la Clínica de la Actividad y la organización de un protocolo técnico de aplicación de la auto-confrontación.

Palabras clave: psicología del trabajo; metodología científica; clínica del trabajo. 
Este artigo pretende elucidar o contexto teórico da produção de uma abordagem da chamada autoconfrontação e contribuir para o seu aprimoramento por meio da apresentação de uma proposta de aplicação desse dispositivo, que tem sido utilizado no Brasil por psicólogos, analistas e pesquisadores do trabalho como mecanismo organizador da intervenção em processos laborais e, também, como instrumento metodológico para a recolha dos dados de investigações acadêmicocientíficas. A autoconfrontação a qual referimos é aquela que foi configurada por Faïta (1997) e apropriada por Vieira e Faïta (2003); Clot (2006; 2010; 2013) e Clot e Fernández (2007) e outros pesquisadores que integram o cenário teórico da Clínica da Atividade.

A estratégia de confrontar o trabalhador com os discursos e os registros feitos acerca do seu ofício e de seus pares, bem como o estabelecimento de nexos entre a atividade linguageira e a modificação do agir de pessoas em situação laboral, surgiu ainda na década de 1970, de acordo com a historicização feita por Theureau (2010) sobre as origens da autoconfrontação. Segundo o autor, Michael von Cranach foi pioneiro na elaboração de uma proposição de autoconfrontação, que emergiu no quadro de estudos da Etologia Cultural. A perspectiva de Cranach foi apreciada criticamente pelo próprio Theureau em parceria com Pinsky (citado por Theureau, 2010) que, a contar de fins dos anos 1970, conceberam a sua visão desse dispositivo metodológico na esfera da Ergonomia e a utilizaram, inicialmente, numa investigação dedicada às questões relativas a ocupação de profissionais da área da enfermagem especializados em ortopedia.

A partir daí, os usos e as possíveis variações dos procedimentos de autoconfrontação têm sido estudadas, discutidas e reelaboradas por inúmeros pesquisadores, tais como: a) Teiger e Laville (1991), que sublinharam a necessidade de os trabalhadores aprenderem a analisar as suas atividades ocupacionais por intermédio do engajamento em situações de estímulo a verbalização e autoconfrontação; b) Salerno (2000), que investigou os elementos caracterizadores da análise ergonômica do trabalho e teceu comentários críticos sobre os usos da autoconfrontação; c) Mollo e Falzon (2004), que empenharam esforços para deslindar as diferentes modalidades de confrontação capazes de conduzir o trabalhador a processos reflexivos sobre a sua atividade (autoconfrontação) ou de outros profissionais (alloconfrontação e allo-confrontação coletiva). Além destas produções sobre a autoconfrontação, temos as elaborações de Faita, Clot e seus colaboradores, que são objeto deste texto.

O interesse pela autoconfrontação, conforme a Clínica da Atividade, se deve ao fato de este dispositivo ter sido configurado para ser caracterizar simultaneamente como um instrumento adequado para suscitar o desenvolvimento humano associado à coanálise, ressignificação e possível transformação da atividade laboral por trabalhadores mediados por um psicólogo, pesquisador ou analista do trabalho e para ser uma ferramenta do campo acadêmico para a recolha e exame de dados sobre o processo de desenvolvimento em situação de trabalho de indivíduos e grupos. Neste sentido, a autoconfrontação extrapola a mera coleta de informações empíricas, observada tradicionalmente nas técnicas metodológicas de pesquisa. Tal dispositivo se singulariza por ser um instrumento interventivo em processos laborais e metodológico-científicos desenvolvido para fazer emergir os múltiplos discursos em torno de um ofício, integrando o estudioso do trabalho e um coletivo de trabalhadores. Deste modo, a autoconfrontação pode favorecer a instalação gradativa de operações dedicadas ao desenvolvimento de pessoas por meio da investigação e compreensão do funcionamento de uma categoria ocupacional e, também, ensejar um movimento dialético de coanálise, produção e apropriação de saberes sobre o trabalho pelos trabalhadores tencionando a sua transformação ou aperfeiçoamento (Clot, 2006), tendo como fundamento que as modificações mais significativas e perenes na laboralidade ocorrem por meio da transmutação conduzida e vivida por aqueles que exercem um ofício.

A despeito das possibilidades que a autoconfrontação traz, observa-se uma lacuna nos estudos especializados brasileiros no que diz respeito a esclarecer as referências teóricas da Clínica da Atividade associadas a este dispositivo. Ainda, nota-se que há um hiato, em nosso país, relativamente às indicações norteadoras da execução da autoconfrontação, tanto por psicólogos e analistas do trabalho interessados em contribuir com trabalhadores que necessitam ampliar o seu raio potencial de desenvolvimento ao modificar ou aperfeiçoar as suas condições ocupacionais, quanto por pesquisadores que a adotam para garantir a coleta dos dados em investigações científicas. Em face disto é que decidimos revisar e discutir as raízes epistemológicas da Clínica da Atividade associadas à autoconfrontação, e metodizar uma proposta de realização das fases e movimentos de aplicação deste 
dispositivo. Cumpre ressaltar que esperamos colaborar para que a autoconfrontação seja utilizada de forma sintonizada e contextualizada com as referências teóricas originais da Clínica da Atividade e, também, oferecer um parâmetro de emprego deste instrumento interventivo e científico capaz de contribuir com o debate em torno da contextualização e adaptação do dispositivo para os cenários ocupacional e científico do Brasil.

Este artigo está organizado em três seções, além desta introdução e das considerações finais, em que são abordadas: as raízes epistemológicas da Clínica da Atividade e as suas relações com a autoconfrontação; a caracterização do dispositivo seguida da apresentação de uma interpretação do ordenamento das suas fases e movimentos. Esclarecemos que foi utilizada neste texto, preferencialmente, a palavra pesquisador para referir ao profissional que faz uso da autoconfrontação, ainda que se saiba que psicólogos e analistas do trabalho adotam o dispositivo em suas ações.

\section{As raízes epistemológicas da clínica da atividade e a produção da autoconfrontação}

A perspectiva da autoconfrontação de Faita (1997) foi elaborada para favorecer a coanálise e o estudo do trabalho dos condutores de trens, e tem sido aprimorada no contexto da Clínica da Atividade, pela equipe do Laboratório de Psicologia do Trabalho do Conservatoire National de Arts e Metiers de Paris (CNAM), sob a coordenação de Clot.

A Clínica da Atividade está situada no campo das Ciências do Trabalho, particularmente na Psicologia do Trabalho e possui como principal raiz epistemológica a Psicologia Histórico-Cultural de Vigotski ${ }^{1}$, segundo o qual o desenvolvimento psicossocial humano ocorre por meio do contato de cada sujeito com outras pessoas e grupos e do estabelecimento de processos colaborativos na mediação da transmissão dos saberes socialmente construídos. O pesquisador russo Vigotski (1926/2004) argumentava que a aprendizagem somente é efetiva quando se observa a apropriação dos conhecimentos e a sua transformação em desenvolvimento real pelo sujeito. De acordo com os seus escritos no livro Pensamento e Linguagem, é preciso que os saberes produzidos socialmente se articulem e sejam incorporados ao universo psíquico e experiencial de cada pessoa (Vigotski, 1934/2008), de modo a favorecer o surgimento, expansão e incremento de instrumentos psicológicos que potencializem a cognição, a afetividade, as ações e a capacidade de lidar criativamente com as complexas situações sociais que irrompem cotidianamente na vida do sujeito.

A abordagem desenvolvimentista vigotskiana norteia a Clínica da Atividade, de acordo com Clot (2010; 2006), na compreensão do trabalho, definido como experiência que permite ao homem, de modo privilegiado, desenvolver a si mesmo e, concomitantemente, alterar o seu meio, em função do estímulo que o trabalho oferece à articulação entre a ação individual e a atividade coletiva, o que faz emergir e consolidar as capacidades de uma pessoa e do grupo. Trata-se de perspectiva ampliada de trabalho, que reconhece a sua relevância para a realização das potencialidades humanas, na mesma medida em que está atenta para o fato de o trabalho se constituir, sob certas circunstâncias, em dimensão que conduz à paralisia da ação, ao sofrimento e ao adoecimento. É sob a influência de Vigotski que a Clínica da Atividade defende a definição do trabalho como um fenômeno ao mesmo tempo social, concreto e psicológico. Além disso, compreende a Psicologia como ciência que deve elaborar e acurar estratégias metodológicas e interventivas que permitam às pessoas e grupos experimentarem a possibilidade de transformação da própria realidade, sobretudo em contexto de trabalho, a ampliação da sua vitalidade e potência de agir e a promoção de metamorfoses emocionais.

Os métodos científicos e da prática psicológica foram examinados por Vigotski (1927/1996) no texto Significado histórico da crise da Psicologia: uma investigação metodológica, em que o autor sustenta que os métodos diretos de acesso ao real limitam o exame e o entendimento das manifestações psíquicas, permitindo somente o contato com as experiências humanas que são acessíveis diretamente pela observação de um pesquisador ou pela percepção da própria pessoa que vivencia o fenômeno, o que ocorreria, por exemplo, por intermédio da introspecção. A Psicologia, os seus profissionais e pesquisadores, deveriam considerar que a "[...] necessidade de sair de uma vez por todas dos limites da experiência direta é assunto de vida ou morte [...]" (Vigotski, 1927/1996, p. 283).

Em função disto, Vigotski apontou que os psicólogos e teóricos da área necessitavam elaborar e desenvolver métodos indiretos de acesso ao psiquismo humano, capazes de favorecer aproximações graduais e sucessivas dos fenômenos psicológicos, que possibilitassem 
visualizar e considerar os comportamentos observáveis e os aspectos conscientes do homem analogamente aos métodos diretos, mas que também permitissem reconstruir e interpretar outras dimensões do psiquismo, não conscientes e subjetivas. O dispositivo nomeado autoconfrontação, conforme concebido no âmbito da Clínica da Atividade, busca atender ao chamado vigotskiano por meio da produção de instrumento metodológico acadêmico e interventivo que pretende favorecer o exame e a compreensão das diferentes esferas do psiquismo humano, investigadas em ambiente de trabalho.

Outra importante referência para a Clínica da Atividade, ainda que pouco mencionada, também na esfera da Psicologia Histórico-Cultural, foi Leontiev (1959/1978; 1974/1983), em particular as suas contribuições para a circunscrição das noções de atividade e trabalho. Tendo como fundamento a visão filosófica materialista, Leontiev caracterizou a atividade como ação concreta dirigida a um objetivo ou finalidade no mundo, que é realizada por um homem em articulação e acordo com outro indivíduo ou com a coletividade. Cada participante de uma atividade é movido por necessidades e motivos presentes em seu psiquismo, os quais estão sintonizados com os interesses e objetivos do pequeno grupo diretamente envolvido na execução de uma atividade. Por fim, os propósitos e intenções de um círculo de pessoas em atividade se conectam, necessariamente, aos aspectos contextuais da sociedade no interior da qual estão enredadas todas as movimentações de uma comunidade. A atividade humana, conforme Leontiev (1974/1983), possui como características centrais: orientar-se por motivações de ordem externa e interna; apresentar propósitos que um indivíduo, socialmente situado e vinculado a um grupo de pessoas, pretende alcançar; dirigir-se a um objeto específico. A adequada compreensão da atividade somente pode ser alcançada considerando as relações dialéticas que se estabelecem entre cada pessoa, o conjunto de indivíduos de uma sociedade e os cenários sociocultural, político e econômico.

Inicialmente, a noção de atividade de Leontiev parece confirmar o pertencimento de Clot e seus colaboradores da Clínica da Atividade à tradição da Psicologia do Trabalho francesa, em que os atos profissionais são incessantemente orientados para objetivos e executados em uma conjuntura social específica e não como tarefas meramente prescritas, descontextualizadas socialmente e desprovidas de sentido para o trabalhador, e que, a despeito disso, por ele devem ser realizadas. Além disso, analogamente a Leontiev, os estudiosos da Clínica da Atividade elegeram a atividade como a sua unidade básica de análise em pesquisas.

Entretanto, cumpre destacar que Clot e os pesquisadores do CNAM se apropriaram e transformaram as concepções do estudioso russo sobre atividade e trabalho para produzir uma unidade analítica original. O trabalho foi delineado por Leontiev como uma atividade socialmente motivada e dirigida a finalidades específicas. Essa conceituação influenciou Clot (2010) na configuração do trabalho como atividade triplamente orientada, na medida em que é "[...] endereçada, dirigida, simultaneamente, para seu objeto e para as outras atividades que incidem sobre esse objetivo, sejam elas do outro ou, ainda de outras atividades do sujeito" (p. 07, grifo do autor). Dito de outra forma, Clot buscou alargar a proposição de Leontiev e passou a preconizar que se deve compreender e examinar o trabalho num modelo triádico, em que a atividade laboral de cada homem é dirigida: a) para si mesmo ou para a denominada dimensão intrapsíquica: b) para o objeto de trabalho, seja ele material ou imaterial; c) para o outro, que pode ser um colega de ocupação, o chefe ou o coletivo profissional.

Essa interpretação triádica de atividade laboral conduziu os teóricos da Clínica da Atividade a sinalizarem para a complexidade da vivência psicológica em situação de trabalho, na medida em que é uma esfera humana marcada pela conflituosidade em múltiplas dimensões, tanto intrapsíquicas, em que os diversos desejos e objetivos internos do indivíduo concorrem mutuamente, quanto sociais, em que os conflitos se manifestam por intermédio dos propósitos e interesses divergentes existentes no universo ocupacional, pelos desacordos e antagonismos entre as múltiplas vozes presentes em cada atividade e, até, pelas resistências e dificuldades impostas pelo próprio objeto do trabalho. Em função do exposto é que Clot destacou que a atividade dirigida deve ser o elemento fundamental de análise da sua clínica do trabalho, concebida como disciplina acadêmica dedicada a apoiar a ampliação da capacidade de agir dos trabalhadores sobre eles mesmos e sobre a esfera ocupacional a qual pertencem. O autor afirmou que ao "[...] escolher a atividade dirigida como unidade elementar de análise na psicologia do trabalho, fazemos uma opção pelo conflito como ponto de partida de pesquisa. Essa atividade dirigida é uma arena, ou melhor, o teatro de uma luta [...]" (Clot, 2006, p. 99).

É preciso salientar que a concepção de atividade de Clot inclui a noção de comportamento humano como um sistema de reações triunfantes de Vigotski 
(1925/1999; 1926/2004), segundo o qual as emoções e condutas observáveis correspondem apenas a uma parte do psiquismo. A energia psíquica que foi impedida de se revelar não desaparece e continua a existir no psiquismo, ainda que no limite da consciência ou de modo inconsciente (Vigotski, 1926/2004), e assume novas formas que se manifestam em outros momentos da vida do indivíduo por meio da expressão reelaborada ou transmutada de afetos, ações e atividades. Isto levou a equipe do CNAM a indicar que a atividade realizada por um trabalhador e observada por um pesquisador seria apenas parte do real, que, em sua totalidade, englobaria as respostas, os sentimentos e as possíveis reações que não foram explicitadas ou que se mantiveram inibidas. De acordo com Clot e Fernandéz (2007) a análise psicológica da atividade e transformações do trabalho, bem como do desenvolvimento humano deve incluir, imperiosamente, as ações suspensas ou impedidas, mas que se mantêm vivas no psiquismo do trabalhador. A autoconfrontação representa justamente o esforço para estruturar uma ferramenta metodológica capaz de estimular o contato do trabalhador com a dimensão não realizada da sua atividade ocupacional, mas que continuou a figurar em suas ações e acometer ou mobilizar a sua cognição e os seus sentimentos, independentemente de as afetações serem conscientes ou inconscientes.

Não obstante isso, é preciso admitir que a perspectiva clotiana e da equipe do CNAM se afastou da abordagem materialista de Leontiev (1959/1978), que identificou na dimensão social e externa ao homem a forma elementar da atividade e enfatizou que a sua transformação em atividade interna se dá no decorrer do processo de internalização, que é a reconstrução intrassubjetiva dos conteúdos e formas simbólicas culturais realizada por um sujeito.

É importante notar que a Clínica da Atividade tem outras inspirações teóricas e metodológicas, para além da Psicologia Histórico-Cultural, dentre as quais se destacam a Ergonomia francófona de Wisner (1987; 1993; 2004), a Psicopatologia do Trabalho de Le Guillant (2006) e os constructos de Oddone (1981; 1986; 2007) sobre Psicologia e mundo do trabalho. A contribuição para a Clínica da Atividade da abordagem teórica de Wisner se relaciona à sua percepção do trabalhador como sujeito social, que atua em situação concreta e real de trabalho, que é afetado e condicionado por sua situação profissional, socioeconômica e política. Trata-se de posição engajada e focalizada na pessoa com e sobre a qual atua o psicólogo ou o ergonomista. Wisner, ainda, rompeu com a visão de Psicologia do Trabalho como ciência meramente aplicada, dedicada à resolução de problemas ocupacionais imediatos. Ele propôs que os atos do trabalhador devem ser compreendidos pela Psicologia de forma situada, isto é, a ação laboral precisa ser visualizada e examinada no cenário em que se realiza, incluindo as dimensões técnica, institucional, econômica, social, política, cultural, entre outras. Essa noção de ação situada do trabalhador é que orienta a Clínica da Atividade e influenciou o aperfeiçoamento da autoconfrontação, de modo a tornar este dispositivo mais que somente um instrumento de recolha de dados para pesquisadores ou de resolução de problemas localizados por trabalhadores.

A visão sobre as doenças ocupacionais e a atenção aos dramas vividos na realidade de trabalho pelos profissionais, em consonância com o que pretendia Le Guillant (2006) em sua Psicopatologia do Trabalho, são enfoques relevantes para compor o quadro conceitual e metodológico da Clínica da Atividade. Em síntese, Le Guillant sinalizou para a importância de analisar as manifestações do sofrimento psicológico de um trabalhador no contexto laboral global, que integra: a) a nocividade do trabalho, que inclui os riscos aos quais o operário está exposto, as demandas e exigências de realização de tarefas que estão acima do que pode ser cumprido, etc.; b) as características e o valor ou insignificância que um ofício assume numa determinada sociedade; c) as exigências e demandas, que muitas vezes são excessivas e difíceis de ser executadas, feitas pelas instituições contratantes a cada pessoa que trabalha; d) a percepção do trabalho como condição social, que contém contradições, afetos e construções objetivas e subjetivas que submetem o trabalhador a experiências que são, simultaneamente, excruciantes, estimulantes e indiferentes ou amorfas. Estas características dissonantes das experiências vividas no espaço profissional conduzem o trabalhador a experimentar concretamente e subjetivamente dissociações, confusões e contradições psíquicas com desdobramentos que podem levar ao padecimento e à doença. A contribuição central de Le Guillant para a Clínica da Atividade está na ênfase em entender o trabalhador individual como parte de uma comunidade social e laboral e, a partir daí, a necessidade de uma clínica do trabalho que amplie as possibilidades de apropriação, pelos homens e mulheres, do seu ofício, favorecendo a compreensão dos seus aspectos constituintes e potencializando os trabalhadores no sentido da transformação da atividade cotidiana, de modo que o processo reformador do trabalho seja capaz de ensejar o desenvolvimento e a ampliação da capacidade de agir pessoal e do coletivo de trabalho. 
No tocante aos constructos e posicionamentos de Oddone, é necessário ressaltar que o pesquisador possuía forte sintonia com os movimentos sociais de trabalhadores da Itália, o que exerceu influência em suas propostas teórico-práticas voltadas para o estímulo ao engajamento e compromisso do estudioso do trabalho com os coletivos de trabalhadores. Esta afinidade de Oddone (2007) com os coletivos organizados de operários concorreu para o destaque que conferiu à necessidade de constante busca, por parte da Psicologia, pela redescoberta e ressignificação da subjetividade dos trabalhadores, valorizando a influência da atividade do coletivo de profissionais para cada pessoa engajada em uma atividade laboral.

A Clínica da Atividade incorporou à sua abordagem a compreensão de Odonne acerca dos aspectos subjetivos e afetivos que estão presentes no trabalho. Nesta perspectiva teórica, cada trabalhador, para realizar a sua ação laboral, recolhe do coletivo de trabalhadores, dos representantes da hierarquia organizacional e, até da própria instituição em que está inserido, parte significativa de sua potência e dos seus recursos de trabalho. Segundo Clot (2010) "[...] se esses recursos se esgotam [...] a vida psicológica de trabalho se encontra gravemente reduzida" (p. 89). Odonne (1986) sugeriu que era necessário à Psicologia elaborar e desenvolver estratégias metodológicas voltadas para a ampliação do poder de agir e da capacidade dos trabalhadores de transformarem a própria realidade. Esta visão parece ter motivado os pesquisadores da Clínica da Atividade a não apenas teorizar ou realizar pesquisas sobre o trabalho, mas criar e aperfeiçoar a autoconfrontação como uma ferramenta interventiva e de modificação de cenários laborais de pessoas e coletivos profissionais.

Os estudiosos da Clínica da Atividade, em suma, têm se dedicado ao aprimoramento de procedimentos metodológicos que se mostrem potencialmente capazes de ensejar o desenvolvimento de pessoas e grupos em situação de trabalho, bem como o exame dos seus desdobramentos e dos modos como o desenrolar das possíveis transformações individuais e coletivas se manifestam num contexto laboral igualmente em estado de transmutação. Nesta abordagem, de acordo com Clot (2006), o trabalho é uma atividade dirigida em situação real, que é composta pelo comportamento observável e pela subjetividade do trabalhador, pelo objeto do labor, pela tarefa objetiva a ser realizada e pelo coletivo de trabalho, constituído pelos colegas, chefes, assistentes, etc. Neste quadro a autoconfrontação tem sido utilizada por ser um dispositivo a um só tempo de coanálise, intervenção e investigação acadêmica do trabalho, que favorece o desenvolvimento dos trabalhadores, que ocorre no fluxo dos movimentos de compreensão e transformação da sua atividade laboral.

Nas próximas seções serão apresentados o delineamento da autoconfrontação e um ordenamento possível das suas diversas fases e movimentos constitutivos.

\section{Caracterização da autoconfrontação}

A autoconfrontação, em conformidade com o que foi esboçado anteriormente, é um dispositivo metodológico voltado para o estímulo ao desenvolvimento das pessoas, que ocorre nos processos de coanálise do trabalho, os quais, por sua vez, sucedem por intermédio do estímulo a experimentação dialógica, a manifestação do plurilogismo profissional e das controvérsias sobre os gestos e as atividades próprias de um ofício determinado, sendo utilizada, ainda, para investigar o agir dos trabalhadores "a fim de ampliar seu raio de ação, seu poder de agir sobre o próprio meio e sobre eles mesmos" (Clot, 2010, p. 208). Neste panorama o instrumento metodológico exige que se estabeleça uma parceria entre o pesquisador e um coletivo de trabalhadores.

Na Clínica da Atividade, o fomento ao desenvolvimento de pessoas e grupos em situação de trabalho apoiados por processos de coanálise e transformação laboral com uso da autoconfrontação tem dois pressupostos básicos, a saber: o primeiro diz respeito à demanda por investigação do trabalho que deve emergir de um grupo de profissionais que percebeu que o exercício das suas funções se encontra degradado (Clot, 2010). Assim, o pesquisador deve ser convidado por um coletivo de trabalhadores, com o suporte da organização em que acontece o trabalho, para contribuir na mediação do processo de (re) apropriação das atividades de ofício pelos profissionais. Esse pressuposto baseia-se na compreensão de que o trabalhador ou grupo de trabalhadores deve identificar e requerer a criação de espaços institucionalmente reconhecidos, bem como a aplicação de mecanismos capazes de apoiar a coanálise e a potencialização das mudanças no agir profissional individual e grupal. A segunda presunção é relativa à concepção da relação entre o sujeito e o coletivo. De acordo com Clot (2010), as situações conflituosas vividas no âmbito pessoal são estabelecidas pela agitação e discussão que emergem nas relações interativas entre os membros de uma 
coletividade humana. Essa conflituosidade social não é entendida de modo negativo por Clot, que avalia que os conflitos sociais ou externos à pessoa contribuem para que o indivíduo mobilize, moureje e coloque em movimento o seu psiquismo. Nesse sentido, é necessário que a autoconfrontação seja aplicada em todas as suas fases para que ocorram aproximações sucessivas na direção do desenvolvimento das pessoas e da produção de saberes pelos trabalhadores acerca do seu próprio ofício e, finalmente, a sua transformação por obra da coletividade profissional. Os dados a serem recolhidos para uma pesquisa científica devem emergir do diálogo que se estabelece entre os próprios trabalhadores e destes com o pesquisador na coanálise das atividades laborais que ocorre durante a aplicação do dispositivo e, de modo privilegiado, no processo dialógico que se busca instalar na fase final da autoconfrontação, nomeada restituição ao coletivo de trabalho. $\mathrm{Na}$ Clínica da Atividade o diálogo inclui, segundo Clot (2006), as formas simbólicas representadas pelos silêncios, impaciências, dúvidas e excitações registradas durante a coanálise do trabalho feita por trabalhadores e pesquisador.

A autoconfrontação se caracteriza por ser uma atividade dirigida, inicialmente por um pesquisador e, depois, pelos próprios trabalhadores, em um processo de diálogo. Neste caso a coanálise da própria atividade laboral pelos trabalhadores, associada à possibilidade de realizar a sua transformação "[...] se revela como um instrumento de desenvolvimento da consciência do sujeito quando Ihe é oferecida a possibilidade de alterar o estatuto do vivido" (Clot, 2010, p. 222).

Para Clot e seus colaboradores da Clínica da Atividade, a confrontação dos profissionais com os seus próprios fazeres e saberes possibilita a desnaturalização e o exame dos atos ocupacionais, bem como, o (re)conhecimento e entendimento da construção única de um coletivo profissional na busca da eficiência no trabalho. Essa criação comum sui generis é denominada gênero social de uma profissão ou gênero profissional (Clot \& Fernández, 2007) e é composta pelos seguintes elementos: a) prescrições e ordenamentos oficiais do trabalho e, também, pelas apropriações destas orientações feitas pelos trabalhadores; b) o modo como as atividades laborais são realizadas por um grupo específico de trabalhadores; c) as avaliações das situações vividas conjuntamente pelos profissionais e as decisões sobre as melhores e mais adequadas formas de agir no cotidiano ocupacional, as quais estruturam e organizam tacitamente a atividade de trabalho.

Em função do exposto é que a autoconfrontação não pode ser concebida apenas como um dispositivo metodológico voltado para o campo das pesquisas por meio do qual os estudiosos realizam coletas de dados. Em verdade, trata-se, primeiramente, de um procedimento de intervenção no trabalho de profissionais que ambicionam ampliar as suas potencialidades e metamorfosear a atividade ocupacional da qual participam. Nesse cenário, é possível compreender o lema transformar para compreender, adotado pelos especialistas da Clínica da Atividade, que evidencia uma visão de desenvolvimento humano que se afasta das abordagens meramente biológicas e cognitivistas, a fim de enfatizar o monismo entre as dimensões afetiva, cognitiva e sociocultural na vivência concreta da construção das capacidades humanas e da mudança das formas de vida.

A realização da coanálise, intervenções e pesquisas acadêmicas com o uso da autoconfrontação demanda do investigador o entendimento da perspectiva clínica que dirige a aplicação deste dispositivo, na qual o trabalho é concebido como operador da saúde psicofísica humana. Isto significa que a autoconfrontação deve ser adotada tendo como horizonte a (re)criação permanente da operação laboral pelos trabalhadores, considerando que somente há saúde nas situações em que a atividade humana está potencializada e em pleno movimento (Clot, 2013). É necessário, também, que o pesquisador domine os procedimentos de execução do dispositivo, de modo que contribua com eficiência e eficácia para o surgimento do diálogo sobre um ofício e a sua transformação pelos trabalhadores. Considerando isto, na próxima seção apresentamos uma sequência possível de encadeamento das fases e movimentos que compõem a autoconfrontação. $O$ ordenamento da utilização do dispositivo parte da presunção de que a demanda - feita por um coletivo de profissionais e por uma instituição - pela realização da coanálise e produção de saberes sobre o trabalho já ocorreu e que o pesquisador fez os esclarecimentos necessários e estabeleceu acordos visando garantir a adequada aplicação da autoconfrontação em parceria com os profissionais e com a organização em que acontecerá o exame e possível aperfeiçoamento ou transformação da atividade laboral. 


\section{Uma leitura das fases e movimentos da autoconfrontação}

Considerando a perspectiva dialética vigotskiana, norteadora da Clínica da Atividade, procuramos apresentar uma leitura das fases e movimentos da autoconfrontação que, por um lado, não é a mera reunião do conjunto de apontamentos já realizado por Clot e seus colaboradores e, por outro, não pretende ser uma prescrição rígida dos usos possíveis do dispositivo. O que se espera é registrar uma referência capaz de estimular o debate e a controvérsia em torno do fazer metodológico por pesquisadores interessados nas referências da Clínica da Atividade. Vale mencionar que o próprio Clot (2014) desencorajou a reprodução do seu trabalho ao afirmar que a mera aplicação ao Brasil dos aportes teóricos e metodológicos da Clínica da Atividade seria desastrosa.

Após este apontamento, podemos indicar que conjecturamos que a autoconfrontação deve ser organizada em três fases articuladas e complementares entre si. Cada fase se subdivide em movimentos distintos a serem seguidos pelo pesquisador. De acordo com Clot e Fernández (2007) a aplicação integral da autoconfrontação ocorre em um ano e seis meses, sendo que cada uma das fases do dispositivo tem duração aproximada de seis meses.

\section{Fase A}

A primeira fase da autoconfrontação objetiva colocar o pesquisador em contato com a atividade laboral e os trabalhadores com os quais atuará. Tratase da aproximação gradual do estudioso em relação ao trabalho e ao coletivo profissional.

Neste período o pesquisador deve conviver com os trabalhadores, de maneira a compreender o métier e tornar-se capaz de contribuir efetivamente ao longo da coanálise. É indesejado que o pesquisador se apresente ou seja percebido apenas como um elemento exterior ao cotidiano que, em breve, desaparecerá do cenário de trabalho sem compreendê-lo e sem colaborar para a produção de saberes e sua apropriação pelos profissionais.

Movimento 1 (documentos prescritivos e contexto sociointeracional de trabalho). Este movimento tem como foco levar o pesquisador a conhecer o contexto sociointeracional de trabalho, recorrendo à identificação e exame dos documentos prescritivos do trabalho dos profissionais participantes da coanálise e pesquisa. Ainda, é realizado o levantamento do histórico de produção desses documentos e quais os usos feitos pelos trabalhadores.

Movimento 2 (composição do grupo de análise). 0 segundo movimento tem início com a composição de um grupo de trabalhadores, junto aos quais sucederá parte significativa da coanálise do trabalho. O grupo deve ser integrado pelo pesquisador e pares de trabalhadores, podendo ser formadas uma, duas, três ou mais duplas de profissionais. Esse agrupamento de trabalhadores e o pesquisador é nomeado grupo de análise (Clot \& Fernández, 2007) ou grupo associado à pesquisa (Clot, 2000) e participará de todas as etapas seguintes de diálogo, exame do trabalho e recolha dos dados. É desejado que este grupo seja formado por profissionais indicados pelo coletivo de trabalhadores, que aceitaram integrar a coanálise e compreenderam que também são voluntários de uma investigação acadêmica. Após, o pesquisador apresenta a autoconfrontação, suas fases e movimentos, bem como esclarece que o objetivo do grupo associado à pesquisa ou de análise voltar-se-á para a produção de saberes sobre a atividade laboral com vistas à sua transformação. É preciso que esses profissionais compreendam que a formação do grupo de análise visa mais que o mero encontro de pessoas, posto que, a partir de agora, idealmente, são parte de uma equipe de diálogo e interpretação das situações laborais, diligentemente dedicada a encorajar o exame do trabalho por cada membro do grupo, que será apoiado e instigado pelas contribuições da coletividade, as quais são levadas a efeito por meio da explicitação das múltiplas perspectivas sobre as possíveis maneiras de execução do trabalho.

Em seguida, o pesquisador faz a observação do trabalho realizado por cada dupla de voluntários e os aspectos relevantes testemunhados são registrados em um diário de pesquisas. Após a observação e registro, uma entrevista semiestruturada deve ser feita com cada um dos trabalhadores para esclarecer dúvidas e detalhar informações. Concomitantemente, o pesquisador orienta os membros de cada dupla de trabalhadores acerca de como proceder na observação do seu colega de atividade profissional, instruindo-os sobre os aspectos técnicos deste instrumento metodológico. Espera-se que os trabalhadores gradualmente se apropriem da observação como ferramenta introdutória de estímulo à reflexão a respeito das semelhanças e diferenças na realização das atividades ocupacionais. As discrepâncias notadas são utilizadas pelos pesquisador como modo de inaugurar 
a dialogia, conflituosidade e coanálise do trabalho. Esta fase é considerada concluída quando os trabalhadores notam que deixaram de ser observados em seu trabalho (pelo pesquisador, pelos seus chefes e colegas) e se tornaram observadores cuidadosos da atividade dos colegas e da sua própria ação laboral. Idealmente, os trabalhadores identificam e demandam ao pesquisador que sejam registradas em áudio e vídeo as atividades de trabalho para facilitar e ampliar o processo coanalítico.

\section{Fase B}

A fase B subdivide-se em três movimentos distintos e tem como objetivo garantir o aprofundamento da coanálise e produção de saberes acerca do trabalho pelas duplas voluntárias, sob a mediação do pesquisador. É feito o registro do trabalho e sua coanálise aspirando que os profissionais, por intermédio do diálogo sobre o seu ofício, tornem-se protagonistas da própria atividade laboral e da sua metamorfose.

Movimento 1 (registro/gravação da atividade de trabalho). Considerando as informações obtidas nas observações e entrevistas, o pesquisador realiza o registro em áudio e vídeo de duas a quatro sequências idênticas de trabalho escolhidas antecipadamente por cada dupla de participantes. O trabalhador é filmado, de 30 a 45 minutos ininterruptos, aproximadamente, na realização das sequências escolhidas com o seu parceiro, de modo a ser possível comparar as formas de conduzir a atividade ocupacional por cada profissional e garantir o diálogo entre os pares. Trata-se da obtenção de dados sobre o trabalho real e/ou real do trabalho (Clot, 2006), que é o trabalho concreto, registrado no momento em que se desenrola a ação. É importante que uma mesma sequência de cada profissional seja registrada em dias e momentos diferentes, para a captação das variadas formas que pode assumir o gesto ocupacional. Ainda, o pesquisador deve estar atento para as possíveis alterações nas condições rotineiras de trabalho, sejam elas produzidas por profissionais parceiros dos voluntários ou por superiores na hierarquia organizacional. Neste caso, o registro não deve ser realizado até que os envolvidos na autoconfrontação e outros agentes intervenientes compreendam a necessidade de um levantamento de informações fidedignas.

Movimento 2 (autoconfrontação simples). Neste movimento, cada profissional assiste a gravação das suas sequências de trabalho. $O$ que se pretende é, por intermédio da exibição do vídeo e do diálogo entre pesquisador e trabalhador, provocar a coanálise do trabalho. O investigador deve elaborar antecipadamente um roteiro de questões, visando organizar o diálogo e estimular o processo reflexivo do trabalhador. Esse roteiro é composto por temas que permitam ao voluntário abordar, entre outras questões, o contexto de realização do trabalho, os aspectos potencializadores e impeditivos ou dificultadores do seu agir profissional, a identificação do foco das suas atividades e a orientação conferida ao trabalho (a que ou quem se dirigem suas ações). Cumpre lembrar que nessa fase cada voluntário assiste ao seu vídeo com o pesquisador, isto é, os profissionais de cada dupla e o grupo de análise não veem os registros conjuntamente. Ainda, este movimento deve ser repetido inúmeras vezes, até que cada trabalhador perceba e sinalize que está ampliando a compreensão sobre a sua atividade, mediante o diálogo com o pesquisador. A instrução ou consigna apresentada a cada trabalhador antes da projeção das sequências laborais é: você assistirá trechos das sequências de trabalho que combinamos previamente que seriam registradas. Sempre que observar ou notar nas imagens situações que mereçam a sua análise, comente o que está vendo. Eu, pesquisador, também solicitarei comentários seus sempre que considerar necessário.

Cada sessão de autoconfrontação simples deve ter duração aproximada de uma hora e ser gravada em áudio e vídeo. O esforço explicativo sobre o próprio trabalho, as pausas, dúvidas, incertezas, manifestações dos pensamentos verbalizados, lacunas discursivas, entre outras manifestações do trabalhador é que compõem a base analítica do pesquisador, que utilizará o material recolhido para subsidiar o desenvolvimento das próximas etapas de aplicação do dispositivo e, também, apoiará as suas aproximações sucessivas em relação ao trabalho analisado.

Movimento 3 (autoconfrontação cruzada). No último movimento da Fase $\mathrm{B}$, o pesquisador e cada dupla de trabalhadores assistem, juntos, as gravações das atividades de trabalho. Trata-se da coanálise e coleta de informações sobre o trabalho interpretado (Clot, 2010), definido como o prolongamento das ações ocupacionais para o campo das análises e reflexões feitas após a realização do trabalho real. Na presença das sequências laborais registradas, o pesquisador deve atuar como mediador do diálogo entre a dupla de trabalhadores, estimulando a identificação de discrepâncias nos modos de cumprir o trabalho por cada profissional. Cada sessão de autoconfrontação cruzada é dedicada ao exame de uma sequência de trabalho de 
cada profissional integrante da dupla. As imagens das ações de cada trabalhador exibidas devem ser analisadas e discutidas com o seu parceiro e com o pesquisador. Neste terceiro movimento a consigna apresentada à dupla de trabalhadores antes da projeção das imagens de cada profissional é: vamos apresentar a sequência de atividades gravadas do trabalhador $X$ (nome do profissional que terá suas imagens exibidas) e solicito os comentários do trabalhador Y (nome do colega de dupla) acerca dos modos ou formas de realizar as atividades do seu companheiro. Na segunda parte da nossa reunião, vou apresentar uma sequência de atividades de $Y$ para que sejam analisadas por $X$ e por mim (pesquisador). $O$ trabalhador que está tendo a sua sequência de trabalho exibida poderá intervir e participar da discussão e da análise do seu trabalho sempre que desejar ou que notar discrepâncias entre o seu modo de agir e aquilo que está sendo dito pelo pesquisador e por seu colega de dupla.

Os movimentos que compõem esta Fase B são considerados exitosos quando conduzem os trabalhadores a descreverem detalhadamente as suas atividades "[...] até que se manifestem os limites dessa descrição, até que a verdade estabelecida seja flagrada na veracidade do diálogo, pela autenticidade dialógica" (Clot, 2010, p. 240). O que surgirá desse processo será, muito provavelmente, um complexo de reflexões sobre os modos de conduzir o trabalho que apoiará o aperfeiçoamento do agir profissional dos participantes. Analogamente ao que ocorre na modalidade simples, a autoconfrontação cruzada deve ser feita inúmeras vezes, até que aflore a conflituosidade acerca das práticas laborais e se instale uma dialogia entre os integrantes do grupo de análise que conduza a uma crescente tomada de consciência das possíveis formas de atuação ocupacional ensejando, por sua vez, a produção de saberes capazes de contribuir para a expansão da potência de ação dos trabalhadores, na perspectiva dos próprios actantes. Ao final, o pesquisador promove reuniões de trabalho em que as duplas compartilham os achados e saberes produzidos sobre a atividade laboral até este momento da autoconfrontação. A sistematização dos conhecimentos construídos deve ser feita por meio de registros escritos pelos próprios trabalhadores e pelo pesquisador, de modo a estimular a apropriação dos achados da coanálise pelos profissionais.

As sessões de entrevistas de autoconfrontação cruzada têm duração aproximada de uma hora e também são gravadas em áudio e vídeo, de maneira que o pesquisador acumule material para a sua investigação acadêmica e para a consulta pelos trabalhadores, caso estes queiram acessar o material.

\section{Fase C}

Esta fase é composta por um longo movimento denominado restituição ao coletivo de trabalho. É o momento em que as descobertas e considerações sobre o trabalho realizadas pelo pesquisador e pelos voluntários (grupo de análise ou associado à pesquisa) são estendidas ao coletivo de trabalhadores que atua na mesma função. Essa submissão dos achados da coanálise ao grupo de trabalho pretende levar o conjunto de trabalhadores a se apropriar dos saberes produzidos, com vistas a estimular a ação engajada dos profissionais objetivando, segundo Clot (2010), a abertura de zonas de desenvolvimento potenciais, isto é, encorajar a reflexão e a ação sobre as possibilidades de transformação da atividade laboral pelos próprios trabalhadores.

Nessa fase, o pesquisador planeja e executa, em parceria com todos os voluntários que participaram das autoconfrontações simples e cruzada, reuniões com o coletivo de trabalho. Essas reuniões podem acontecer com "o coletivo profissional [...]; o comitê de monitoramento da intervenção; o coletivo profissional ampliado, ou seja, o conjunto dos pares [...]" (Clot, 2010 , p. 241). Devem ser realizadas tantas reuniões quantas forem necessárias para a criação das condições que conduzam os trabalhadores ao planejamento e implementação de um projeto de aperfeiçoamento ou transformação do seu processo laboral.

Analogamente ao que ocorreu nas fases anteriores, as reuniões de restituição ao coletivo são registradas pelo pesquisador que, conforme mencionado anteriormente, terá como material privilegiado de pesquisa o próprio processo dialógico e de transformação do trabalho. O ponto central da investigação científica estará no exame e compreensão do modo como a atividade laboral degradada se apresentava no momento da demanda dos trabalhadores pela coanálise do trabalho e, principalmente, no estudo do processo que se desenredou no sentido da produção, apropriação de saberes e transformação do trabalho pelas duplas de voluntários e, posteriormente, pelo coletivo de trabalhadores.

\section{Considerações finais}

À guisa de conclusão é relevante lembrar que este artigo apresentou e discutiu os fundamentos epistemológicos da Clínica da Atividade que geraram as 
condições para a apropriação e configuração do dispositivo de desenvolvimento humano, coanálise e investigação sobre o trabalho denominado autoconfrontação. Em seguida, buscou-se caracterizar e apresentar um conjunto de referências para contribuir com os debates em torno dos usos deste dispositivo por psicólogos, analistas do trabalho e pesquisadores brasileiros.

O estudo teórico realizado teve características exploratórias e, em função disso, há limitações que não se pode negar, e parece adequado sinalizar que: a) existe a necessidade de outras produções acadêmicas dedicadas à difusão de leituras e modos de compreensão da autoconfrontação, inspiradas no quadro teórico da Clínica da Atividade, que contribuam para a sua contextualização para a realidade do mundo do trabalho e do cenário acadêmico científico brasileiros; b) é preciso que estudos de campo confirmem a pertinência da interpretação, aqui apresentada, das formas de uso do dispositivo; c) reconhecemos que o papel desempenhado pelo analista do trabalho ou pesquisador no uso da autoconfrontação demanda investigações ulteriores, que permitam conhecer e propor técnicas e estratégias, sintonizadas com a Psicologia Histórico-Cultural, de mediação do desenvolvimento humano por meio da imersão de trabalhadores em movimentos de transformação e coanálise do trabalho protagonizado por coletivos operários.

A despeito disso, consideramos que a autoconfrontação, ao enfocar e valorizar a experiência e as reflexões do trabalhador objetivando potencializar a sua capacidade transformadora, se configura como ferramenta valiosa para a compreensão e o estímulo à metamorfose dos espaços laborais protagonizadas pelos próprios trabalhadores. Por fim, vale reafirmar que não tivemos a pretensão de veicular uma interpretação unívoca deste dispositivo, mas contribuir com uma provável referência de sua aplicação, vinculada aos princípios da Psicologia Histórico-Cultural, bem como colaborar com uma interpretação das raízes epistemológicas da Clínica da Atividade diretamente associadas à autoconfrontação, as quais podem ser adotadas com vistas a promover o movimento e a saúde biopsicossocial do homem tendo o trabalho como unidade singular de desenvolvimento humano.

\section{Referências}

Clot, Y. (2000). A formação pela análise do trabalho: por uma terceira via em maneiras de agir, maneiras de pensar em formação. (C. Silva, K. Santorum \& S. Baker, Trads.). Paris: CNAM, 2000. Recuperado de http://www. pqv.unifesp.br/AformacaoatravesdaanalisedotrabalhoYvesClot.pdf
Clot, Y. (2006). A função psicológica do trabalho (A. Sobral, Trad.). Petrópolis, RJ: Vozes.

Clot, Y. (2010). Trabalho e poder de agir (M. Vianna \& G. Teixeira, Trads.). Belo Horizonte, MG: Fabrefactum.

Clot, Y. (2013). O ofício como operador da saúde. Cadernos de Psicologia Social do Trabalho. 16(1), 1-11. doi: 10.11606/issn.1981-0490. v16ispe1p1-11.

Clot, Y. (2014). Prefácio. In D. S. Rosemberg, J. R. Filho, \& M. E. Barros (orgs.), Trabalho docente e poder de agir: Clínica da Atividade, devires e análises (pp. 11-14). Vitória: EDUFES.

Clot, Y., \& Fernández, G. (2007). Instrumentos de investigación: entrevistas en auto-confrontación: un método en clínica de la actividad. Laboreal, 3(1), 15-19. Recuperado de http://laboreal.up.pt/pt/ articles/entrevistas-de-auto-confrontacao-um-metodo-na-clinica-da-actividade/

Faïta, D. (1997). La conduite du TGV: exercices de styles. Champs Visuels, 2(6), 75-86.

Le Guillant, L. (2006). Le drame humain du travail: essais de psychopatologie du travail. Paris: Érès.

Leontiev, A. (1978). Sobre o desenvolvimento histórico da consciência (R. Frias, Trad.). In A. Leontiev (Org.), O desenvolvimento do psiquismo (pp. 89-142). Lisboa: Horizonte Universitário (Obra original publicada em 1959)

Mollo, V.; \& Falzon, P. (2004). Auto- and allo-confrontation as tools for reflective activities. Applied Ergonomics, 35(6), 531-540. doi: 10.1016/j.apergo.2004.06.003

Odonne, I. (1981). Redécouvrir l'expérience ouvrière: vers une autre psychologie du travail? Paris: Éditions Sociales.

Oddone, I, (1983). Actividad, conciencia e personalidad. Havana: Editorial Pueblo y Educación (Obra original publicada em 1974)

Oddone, I. (1986). Ambiente de trabalho: a luta dos trabalhadores pela saúde. São Paulo: Hucitec.

Oddone, I. (2007). Reflexiones sobre el modelo obrero italiano. Revista Sindical, 5(2), 4-9.

Salerno, M.S. (2000). Análise ergonômica do trabalho e projeto organizacional: uma discussão comparada. Produção, 9(num. especial), 45-60. doi:10.1590/S0103-65131999000400003

Teiger, C., \& Laville, A. (1991). L'aprentissage de l'analyse ergonomique du travail, outil d'une formation pour l'action. Travail et Emploi, 47, 53-62.

Theureau, J. (2010). Les entretiens d'autoconfrontation et de remise en situation par les traces matérielles et le programme de recherche "cours d'action». Revue d'anthropologie des Connaissances, 4(2), 287-322. Recuperado de http://www.cairn.info/revue-anthropologie-des-connaissances-2010-2-page-287.htm

Vieira, M.; \& Faïta, D. (2003). Quando os outros olham outros de si mesmo: reflexões metodológicas sobre a autoconfrontação cruzada. Polifonia, 7(1), 27-65. Recuperado de http://periodicoscientificos. ufmt.br/ojs/index.php/polifonia/article/view/1137

Vigotski, L. S. (1999). Psicologia da arte (P. Bezerra, Trad.). São Paulo: Martins Fontes (Obra original publicada em 1925).

Vigotski, L. S. (2004). Psicologia pedagógica (P. Bezerra, Trad.). São Paulo: Martins Fontes (Obra original publicada em 1926)

Vigotski, L. S. (1996). O significado histórico da crise da Psicologia: uma investigação metodológica (C. Berlinder, Trad.). In L. S. Vigotski (Org.), Teoria e método em Psicologia (pp. 203-417). São Paulo: Martins Fontes (Obra original publicada em 1927) 
Vigotski, L. S. (2008) Pensamento e linguagem (P. Bezerra, Trad.). São Paulo: Martins Fontes (Obra original publicada em 1934)

Wisner, A. (1987). Por dentro do trabalho, ergonomia: método e técnica (F. Vezzá, Trad.). São Paulo, FTD/Oboré.
Wisner, A. (1993). A inteligência no trabalho: textos selecionados de ergonomia. São Paulo: Fundacentro.

Wisner, A. (2004). Questões epistemológicas em ergonomia e em análise do trabalho. In F. A. Daniellou (Org.), Ergonomia em busca de seus princípios: debates epistemológicos. (pp. 29-56). São Paulo: Edgar Blücher.

${ }^{1}$ Nesse trabalho optou-se por adotar a grafia Vigotski, conforme as traduções das obras do pensador russo para o português, realizadas por Paulo Bezerra.

Deivis Perez, Doutor em Educação pela Pontifícia Universidade Católica de São Paulo (PUC-SP), é Professor Doutor do Programa de Pós-Graduação em Psicologia e Departamento de Psicologia Social e Educacional na Universidade Estadual Paulista Júlio de Mesquita Filho (UNESP). Endereço para correspondência: Avenida

Dom Antonio, 2100 - Bairro Parque Universitário - CEP: 19806900 - Assis/SP. Telefones: (18) 3302-5800 e (18) 98102-5282. E-mail: prof.deivisperez@hotmail.com 